\title{
Self-reported data on medicine use in the Norwegian Mother and Child cohort study compared to data from the Norwegian Prescription Database
}

\author{
Svetlana Skurtveit ${ }^{1,2}$, Randi Selmer ${ }^{1}$, Ingvild Odsbu ${ }^{1}$ and Marte Handal ${ }^{1}$ \\ ${ }^{l}$ Norwegian Institute of Public Health, Division of Epidemiology, P.O.Box 4404 Nydalen, Oslo, Norway \\ ${ }^{2}$ Norwegian Centre for Addiction Research, University of Oslo, Norway
}

Correspondence: svetlana.skurtveit@fhi.no

\begin{abstract}
Aims: To study information on prescribed drug use (opioids, antidepressants and benzodiazepines (BZD)) recorded in the Norwegian Prescription Database (NorPD) and to compare this information with selfreported drug use among pregnant women in the Norwegian Mother and Child Cohort Study (MoBa).

Materials and methods: The study population consisted of 28479 women who participated in MoBa and who answered all questionnaires in pregnancy and whose pregnancy started after 1 March 2004. Data on dispensed drugs in NorPD were extracted for three different time windows: a) the pregnancy period, b) 30 days prior to pregnancy in addition to pregnancy, c) 60 days prior to pregnancy in addition to pregnancy. Data on self- reported drug use in MoBa were used as the reference standard in the validity analysis. Sensitivity and specificity were calculated.

Results: Sensitivity of drug use as recorded in NorPD for the pregnancy period was highest for antidepressants $(66.9 \%)$ and BZD-antiepileptics (100\%) and lowest for BZD-anxiolytics (44.8\%) and BZDhypnotics $(27.8 \%)$. Expansion of the time windows for dispensed drugs in the NorPD to include intervals 30 and 60 days before pregnancy led to higher sensitivity, but lower specificity of all classes of drugs. For opioids, sensitivity increased from $48.8 \%$ to $53.6 \%$, while specificity decreased from 98.7 to $97.6 \%$. For antidepressants and BZD-anxiolytics, specificity decreased for both from 99.7 to $99.4 \%$.

Conclusion: Using self-reported data as reference standard, the prescription data provides valid information on current exposures to BZD-antiepileptics and antidepressants in pregnant women if time windows are selected with adequate consideration depending on the investigated problem. However, validity is lower for other benzodiazepines and opioids.
\end{abstract}

This is an open access article distributed under the Creative Commons Attribution Licence, which permits unrestricted use, distribution, and reproduction in any medium, provided the original work is properly cited.

\section{INTRODUCTION}

According to studies from Europe and the United States many women use prescribed drugs during pregnancy (1-4). However, there is limited knowledge with regard to possible adverse effects of such use for both the mother and the fetus. Pregnant women are not included in clinical trials, and observational studies are therefore essential in drug safety studies.

In Norway different data sources on drug exposure in pregnancy exist. The Medical Birth Registry (MBRN) has information on drug use from standardized antenatal medical records (5). In the Norwegian Prescription Database (NorPD) information on all dispensed drugs from pharmacies to outpatients is collected (6). Pregnant women participating in the Norwegian Mother and Child Cohort Study (MoBa) self-report drug use as pregnancy progresses (7).

Even though more than half of pregnant women use some kind of prescribed drug during pregnancy, only a small number use a specific drug (2). Many relevant birth complications and long term outcomes in children are infrequent. Because both exposure and outcomes can be rare, large study samples are required to have the required statistical power when studying association between drug exposure and different birth or later complication in child. In the field of observational drug safety studies, nationwide prescription databases have to larger extent begun to be used as a source of drug exposure information (8). Even assembling data from several nationwide prescription databases have been necessary to study very rare outcomes (9).

The truth regarding drug use in pregnancy is not available either in the prescription databases or when information on drug use is self-reported. The main limitation regarding the use of prescription databases is whether and when the dispensed medication is actually ingested by the patient. Thus it has been pointed out that a major challenge in prescription database studies is to validate exposure (10).

In Norway we have information on self-reported drug use among women participating in $\mathrm{MoBa}$ at the same time as we have information on prescription data from NorPD. Pregnant women are generally cautious when it comes to using medicines. Participants in $\mathrm{MoBa}$ were motivated to participate and recall bias is also minimized because the women mainly reported on 
drug use before the outcome was known. In addition the recall time on drug use was short in MoBa. Data on self-reported drug use in $\mathrm{MoBa}$ is therefore suitable as the reference standard in the validity analysis.

The main aim of the present study was to study information on some prescribed drug groups recorded in the NorPD and to compare this information with selfreported drug use among pregnant women in MoBa. Drug groups used for chronic conditions (antidepressants and benzodiazepine (BZD)-antiepileptics) and drugs often used intermittently (opioids, BZDanxiolytics and BZD-hypnotics) were investigated.

\section{MATERIALS AND METHODS}

The present study is based on the MoBa and the NorPD. Data from MoBa and NorPD were linked using the unique personal identity number assigned to all individuals living in Norway. Data from MoBa on the use of drugs reported by pregnant women were compared with data on dispensed drugs recorded in NorPD.

\section{The Norwegian Mother and Child Cohort Study (MoBa)}

$\mathrm{MoBa}$ is a prospective population-based pregnancy cohort study conducted by the Norwegian Institute of Public Health (11). Participants were recruited from all over Norway from $1999-2008$, and $38.5 \%$ of the invited women consented to participate. The cohort now includes 108000 children, 90700 mothers and 71500 fathers. Follow-up is conducted by questionnaires at regular intervals and by linkage to national health registries. Several sub-studies are conducting additional collections of data and biological materials. Some of the information in MoBa is obtained from the MBRN. MBRN is a nationwide registry that is based on compulsory notification of every birth or late abortion from 12 weeks of gestation onwards in Norway (12). The current study is based on version 5 of the qualityassured data files.

\section{The Norwegian Prescription Database (NorPD)}

From January 2004, all Norwegian pharmacies have been obliged to send data electronically each month to the Norwegian Institute of Public Health on all prescribed drugs (irrespective of reimbursement) redeemed by individuals in ambulatory care (6). Variables from NorPD used in our study were unique encrypted personal identity number, date of dispensing, and information on drugs dispensed. All drugs in Norway are classified according to the Anatomical Therapeutic Chemical (ATC) Classification System (13).

\section{Study drugs}

Drugs included in our study are opioid analgesics (ATC-group N02A), drugs for treatment of depression (antidepressants, N06A), drugs for anxiety (BZDanxiolytics, N05BA), sleeping pills (BZD-hypnotics, N05CD) and antiepileptics (BZD-antiepileptics, N03AE). Opioids, BZD-anxiolytics and BZD-hypno- tics are often used intermittently, but antidepressants and antiepileptics are used for chronic conditions. Drugs were studied as ATC chemical subgroup. For example, if a woman used two BZD-anxiolytics in the same ATC subgroup (e.g. diazepam N05BA01and oxazepam N05BA04), the woman was recorded as "positive" for the class of drugs named BZDanxiolytics (N05BA).

\section{Exposure definition}

Self-reported drug use in MoBa

The mother received three questionnaires with questions regarding drug use in pregnancy (questionnaire 1 (Q1), 3 (Q3) and 4 (Q4)) (14). Pregnant women received a postal invitation to participate in MoBa prior to their first ultrasound scan between gestational weeks 17 and 18. The first questionnaire Q1 which asked about drug use covered the time period from 6 months before pregnancy to the 18th gestational week. The questionnaire Q3 covered the time period between the $19^{\text {th }}$ and $29^{\text {th }}$ gestational week and the questionnaire Q4 covered the time period from the $30^{\text {th }}$ gestational week and was answered by the women when the child was around 6 months old.

Parts of all the questionnaires presented in figure 1 show how the questions on use of medicine were phrased. Complete questionnaires are available on the Norwegian Institute of Public Health's web site (14). In Q1 women were asked if they previously have had or currently have different types of illnesses or health problems and whether they have used drugs for these conditions. The women were asked if they have had a specific condition before or during pregnancy and on the same line, whether they have used drugs six months before pregnancy and/or during pregnancy weeks 0-4, 5-8, 9-12 and 13+. 53 illnesses in seven groups (asthma/allergy/skin disorders; diabetes; hearth/blood/metabolism/blood vessels; gastrointestinal; muscle/skeleton/connective tissue; genital/urinary tract; other illnesses/health problems) were examined in this way (figure 1a). In another question in Q1, women were asked about other specific illnesses / health problems during pregnancy by means of 24 questions (figure 1b). In this question the women were only asked about illnesses/health problems and use of drugs during (and not before) pregnancy. In the last question the woman could write down medication she had used the last six months or during pregnancy that she did not mention before. The time intervals of drug use during pregnancy in the two last questions were the same as in the first question (figure 1c).

In the questionnaire Q3 (around pregnancy week 30) women were asked about illnesses/health problems and the use of drugs in four-week intervals from week 13 to week 28, and from week 29 onwards (figure 1d). In the last questionnaire Q4 (when the child was about 6 months) the woman answered questions about the last part of pregnancy and the time after pregnancy (figure 1e). 


\section{a) Previous and current illnesses and health problems}

39. Do you have or have you had any of the following illnesses or health problems? If you have taken medication (tablets, mixtures, suppositories, inhalers, creams, etc.) in conjunction with the illness or health problem give the name(s) of the medication(s) and when you took them.

b)

\begin{tabular}{|c|c|c|c|c|c|c|}
\hline \multirow[b]{3}{*}{ IIIness/health problem } & \multirow{3}{*}{$\begin{array}{l}\text { Before } \\
\text { Pregnancy }\end{array}$} & \multirow{3}{*}{$\begin{array}{l}\text { During } \\
\text { Pregnancy }\end{array}$} & \multicolumn{3}{|c|}{ Use of medication } & \multirow{3}{*}{$\begin{array}{c}\text { Number } \\
\text { of days } \\
\text { used }\end{array}$} \\
\hline & & & \multirow[b]{2}{*}{ Name of medicines } & \multirow{2}{*}{$\begin{array}{c}\text { Last } 6 \\
\text { months } \\
\text { before } \\
\text { pregnancy }\end{array}$} & Pregnancy week & \\
\hline & & & & & $\begin{array}{llll}0-4 & 5-8 & 9-12 & 13+\end{array}$ & \\
\hline
\end{tabular}

52 Anxiety

38. Have you experienced any of the following illnesses or problems during this pregnancy? If you have used medication in connection with these problems give the name of the medicine, the weeks you took the medicines and how many days you took them. (Include all types of medication, both prescription and over the counter medicines in addition to alternative and herbal remedies. Do not include

Q1 vitamins and dietary supplements as these are discussed elsewhere.)

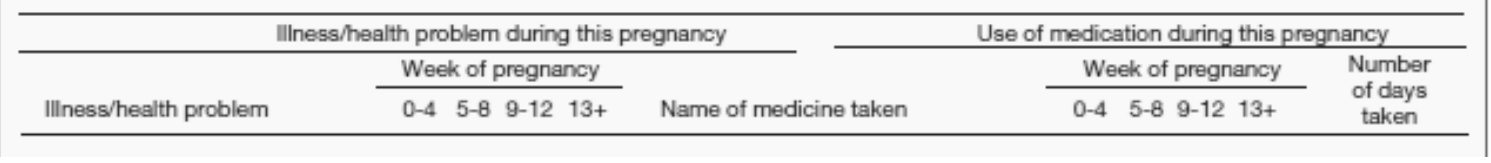

c)

Other medicines

44. Have you used other medication not previously mentioned? If yes, which and when did you take them?

Use of medication during pregnancy weeks

Name of medication

Name of medication
(e.g. Valium, Rohypnol, Paracetamol)

Q1

\begin{tabular}{ccccc||c|}
$\begin{array}{c}\text { Last } 6 \text { months } \\
\text { before pregnancy }\end{array}$ & $0-4$ & $5-8$ & $9-12$ & $13+$ & $\begin{array}{c}\text { Number } \\
\text { of days used }\end{array}$ \\
\cline { 2 - 6 } & $\square$ & $\square$ & $\square$ & $\square$ & \\
$\square$ & $\square$ & $\square$ & $\square$ & $\square$ & \\
$\square$ & $\square$ & $\square$ & $\square$ & $\square$ & \\
$\square$ & $\square$ & $\square$ & $\square$ & $\square$ & \\
$\square$ & $\square$ & $\square$ & $\square$ & $\square$ &
\end{tabular}

52. Do you have or have you had any of the following illnesses or problems after the 13th week of pregnancy? If you have used tablets, mixtures, suppositories, inhalers, creams, etc. in connection with the illness or problem, give the name(s) of the medication(s), when and how long you took them. (Fill in one or more boxes.) (This applies to all types of medicines including alternative and herbal remedies, both regular and occasional use. Do not include vitamins and nutritional supplements as these are asked about elsewhere.)

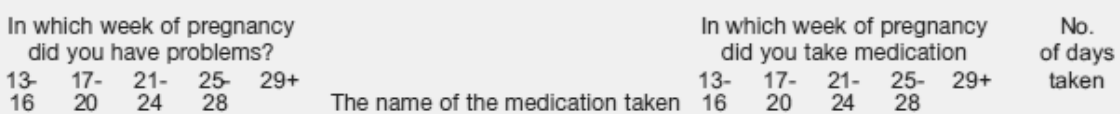

Q3

2 Back pains

$\square \square \square \square \square$

$\square \square \square \square \quad \square$

e)

53. Have you had any of the following problems/illnesses since you completed the previous questionnaire? If yes, are you taking or have you taken medication for these problems? (This includes every type of medication, including natural medicines, taken on both a regular and occasional basis.) (Enter a cross in a box for each item.)

Have you suffered from?

Q4

If you have taken medication

Name of medication taken

\begin{tabular}{|c|c|c|c|}
\hline \multirow{2}{*}{$\begin{array}{l}\text { Last } \\
\text { part of } \\
\text { this } \\
\text { pregnancy }\end{array}$} & \multicolumn{2}{|c|}{ After the birth } & \multirow{2}{*}{$\begin{array}{c}\text { Number } \\
\text { of days } \\
\text { taken } \\
\text { in total }\end{array}$} \\
\hline & $\begin{array}{l}0-3 \\
\text { mth }\end{array}$ & $\begin{array}{l}4-6 \\
\text { mth }\end{array}$ & \\
\hline$\square$ & $\square$ & $\square$ & \\
\hline
\end{tabular}

Figure 1. The phrasing of the questions on use of medicine. The mothers participating in the Norwegian Mother and Child Cohort Study $(\mathrm{MoBa})$ received three questionnaires $(\mathrm{Q} 1, \mathrm{Q} 3, \mathrm{Q} 4)$ with questions regarding medicine use during pregnancy that cover the (Q1) period from 6 month before pregnancy to the $18^{\text {th }}$ gestational week, (Q3) period from the $19^{\text {th }}$ to the $29^{\text {th }}$ gestational week and (Q4) period from the $30^{\text {th }}$ gestational week until the child was around 6 months old. 
The answers on the drug questions were converted into ATC codes by trained personnel. Women were defined as users of the various medications during pregnancy if they had written a drug and at the same time ticked a box that indicated that they had used the drug during pregnancy in one of the three questionnaires, independently on which illness/health problem they had used the drug for.

The participants could write down more than one drug as a response to one question (figures $1 \mathrm{a}$ and 1c) and they could tick for several periods of use. In situations with several drugs used in several time periods it was difficult to disentangle which specific drug that was used in which specific period. Women who ticked both the period before or after pregnancy and one of the time periods during pregnancy and wrote more than one drug on the same line were excluded from the analysis.

\section{Drug exposure from NorPD}

When studying drug use in pregnancy using a prescription database, it is common to define a woman as drug exposed if she was dispensed the drug not only during pregnancy but also during a predefined period before pregnancy; the rationale being that the drug supplied from the pharmacy could result in treatment that lasted beyond the start of pregnancy (15). To show the effect of such practice on validity, pregnancy was in NorPD defined in three different ways with increasing periods before pregnancy included in the exposure time window (figure 2). A woman was defined as exposed if she was dispensed drugs at least once during the defined exposure period. The three definitions of pregnancy in NorPD were as follows: (i) no inclusion of time before pregnancy until birth, (ii) inclusion of 30 days before pregnancy until birth, and (iii) inclusion of 60 days before pregnancy until birth. As an example, a woman would be classified in group (ii) as exposed in NorPD if she was dispensed opioids during the 30 days before pregnancy with or without receiving opioids during the days of pregnancy. She would also be classified as exposed in group (iii).

\section{Study population}

This study is based on data from pregnant women who participated in MoBa whose pregnancy began after 1 March 2004 and where the women answered all the three questionnaires $(\mathrm{N}=29220)$. For women with multiple pregnancies, only data from the first pregnancy after 1 March 2004 was used. The study population thus consisted of 28479 women. Data in NorPD are collected from 1 January 2004. Thus, in order to obtain a 60 days follow-up period for all women in our study population, we included women in MoBa whose pregnancy began after 1 March 2004.

Because of the difficulty with disentangling which specific drug was used in which specific period we excluded some women from the analyses (figure 1a and 1d), 66 women concerning the use of opioids; 0 women concerning the use of antidepressants; 8 women concerning use of BZD-anxiolytics, 1 woman concerning use of BZD-hypnotics and 2 women concerning use of BZD-antiepileptics.

\section{Analysis strategy}

Data on dispensed drugs to pregnant women from NorPD were compared with self-reported data from the MoBa questionnaires (figure 2). Data on selfreported drug use in $\mathrm{MoBa}$ were used as the reference standard in the validity analysis. Different exposure time windows in NorPD were compared with selfreported drug use during pregnancy. Data on dispensed drugs from NorPD were extracted for each responder for three different time windows: (i) the pregnancy period, (ii) 30 days prior to pregnancy in addition to the pregnancy period, and (iii) 60 days prior to pregnancy in addition to the pregnancy period. Time windows (ii) and (iii) were chosen to capture that drugs dispensed before pregnancy possibly were used by the woman during pregnancy.

Two measures of validity (sensitivity and specificity) were calculated with $95 \%$ confidence intervals (CIs) by the continuity-corrected score interval method (16).

Statistical analyses were conducted using SPSS for Windows, 17.0.1; SPSS Inc., Chicago, IL.

\section{Ethics}

This MoBa sub-study was approved by the Regional Committee for Medical and Health Research Ethics South-East and the record linkage was approved by The Norwegian Data Inspectorate. Informed consent was obtained from mothers before inclusion in MoBa.

\section{RESUlts}

\section{Prevalence of self-reported drug use in MoBa and dispensed drugs as recorded in NorPD}

Table 1 compares self-reported drug use in MoBa with dispensed drugs in NorPD (three definitions). Prevalence of dispensed opioids and BZD-anxiolytics recorded in NorPD for pregnant women were higher than self-reported drug use prevalence (table 1). For opioids, $2.1 \%$ filled prescriptions during pregnancy and a lower proportion $(1.6 \%)$ of women self-reported use of opioids. For antidepressants, $1 \%$ of women self-reported use of antidepressants and the same proportion filled prescriptions during pregnancy.

Prevalence of women who were dispensed opioids increased from $2.1 \%$ to $2.6 \%$ and $3.2 \%$ when the periods for dispensed opioids in NorPD were expanded to 30 and 60 days before pregnancy, respectively. Prevalence of women who were dispensed antidepressants increased to $1.3 \%$ and $1.5 \%$ when the periods for dispensed antidepressants in NorPD were expanded to 30 and 60 days before pregnancy, respectively. 
MoBa

NorPD

(i)

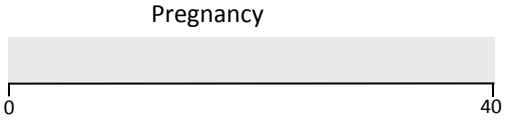

(ii)

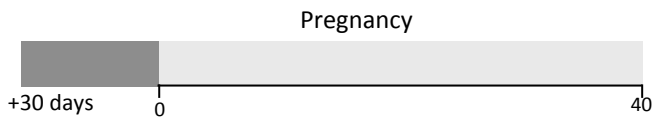

(iii)

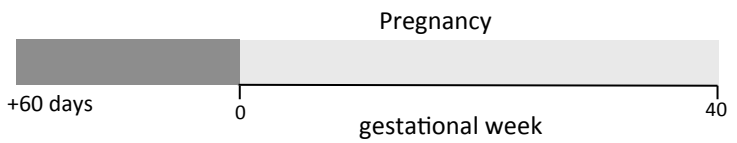

Figure 2. Data on dispensed antidepressants, benzodiazepines and opioids to pregnant women from the Norwegian Prescription Database (NorPD) were compared with self-reported data from the Norwegian Mother and Child Cohort Study (MoBa) questionnaires. The participants in MoBa received three questionnaires with question regarding drug use. A woman was defined as exposed if she was dispensed drugs at least once during the defined exposure period. The three definitions of pregnancy in NorPD were as follows: (i) no inclusion of time before pregnancy until birth, (ii) inclusion of 30 days before pregnancy until birth, and (iii) inclusion of 60 days before pregnancy until birth.

Table 1. Comparison between drug exposure based on the Norwegian Prescription Database (NorPD) for different time periods and self-reported data from the Norwegian Mother and Child Cohort Study (MoBa). Self-reported drug use as recorded in MoBa was used as the reference standard in the validity analysis of dispensed drugs as recorded in NorPD. Two measures of validity (sensitivity and specificity) were calculated with $95 \%$ confidence intervals (CI).

\begin{tabular}{|c|c|c|c|c|c|c|c|c|c|c|c|c|c|c|c|}
\hline \multirow[b]{3}{*}{ Drug category } & \multicolumn{6}{|c|}{ Prevalence } & \multirow{3}{*}{ 1) } & \multirow{3}{*}{ 2) } & \multirow{3}{*}{ 3) } & \multirow{3}{*}{ 4) } & \multirow{3}{*}{$\frac{\text { Total; N }}{\mathrm{N}}$} & \multirow{2}{*}{\multicolumn{2}{|c|}{ Sensitivity * }} & \multirow{2}{*}{\multicolumn{2}{|c|}{ Specificity $* *$}} \\
\hline & & lf-repc & ort MoBa & & & $\mathrm{PPD}$ & & & & & & & & & \\
\hline & $\mathrm{N}$ & $\%$ & $95 \% \mathrm{CI}$ & $\mathrm{N}$ & $\%$ & $95 \% \mathrm{CI}$ & & & & & & $95 \% \mathrm{CI}$ & & $95 \% \mathrm{CI}$ & \\
\hline Opioids, during pregnancy & 457 & 1.6 & $1.5-1.8$ & 589 & 2.1 & $1.9-2.3$ & 27615 & 366 & 234 & 223 & 28438 & 48.8 & $44.1-53.5$ & 98.7 & $98.6-98.8$ \\
\hline $\begin{array}{l}\text { Opioids, dispensed from } 30 \text { days before } \\
\text { pregnancy or during pregnancy }\end{array}$ & & & & 738 & 2.6 & $2.4-2.8$ & 27476 & 505 & 224 & 233 & 28438 & 51.0 & $46.3-55.6$ & 98.2 & $98.0-98.4$ \\
\hline $\begin{array}{l}\text { Opioids, dispensed from } 60 \text { days before } \\
\text { pregnancy or during pregnancy }\end{array}$ & & & & 918 & 3.2 & $3.0-3.4$ & 27308 & 673 & 212 & 245 & 28438 & 53.6 & $48.9-58.2$ & 97.6 & $97.4-97.8$ \\
\hline Antidepressants, during pregnancy & 299 & 1.0 & $0.9-1.2$ & 279 & 1.0 & $0.8-1.1$ & 28101 & 79 & 99 & 200 & 28479 & 66.9 & $61.2-72.1$ & 99.7 & $99.7-99.8$ \\
\hline $\begin{array}{l}\text { Antidepressants, dispensed from } 30 \text { days } \\
\text { before pregnancy or during pregnancy }\end{array}$ & & & & 369 & 1.3 & $1.2-1.4$ & 28053 & 127 & 57 & 242 & 28479 & 80.9 & $75.9-85.1$ & 99.5 & $99.5-99.6$ \\
\hline $\begin{array}{l}\text { Antidepressants, dispensed from } 60 \text { days } \\
\text { before pregnancy or during pregnancy }\end{array}$ & & & & 430 & 1.5 & $1.4-1.7$ & 28010 & 170 & 39 & 260 & 28479 & 87.0 & $82.5-90.5$ & 99.4 & $99.3-99.5$ \\
\hline BZD***-anxiolytics, during pregnancy & 96 & 0.34 & $0.27-0.41$ & 129 & 0.45 & $0.38-0.54$ & 28289 & 86 & 53 & 43 & 28471 & 44.8 & $34.8-55.3$ & 99.7 & $99.6-99.8$ \\
\hline $\begin{array}{l}\text { BZD***-anxiolytics, dispensed from } 30 \\
\text { days before pregnancy or during pregnancy }\end{array}$ & & & & 180 & 0.63 & $0.54-0.73$ & 28244 & 131 & 47 & 49 & 28471 & 51.0 & $40.7-61.3$ & 99.5 & $99.5-99.6$ \\
\hline $\begin{array}{l}\text { BZD***-anxiolytics, dispensed from } 60 \\
\text { days before pregnancy or during pregnancy }\end{array}$ & & & & 218 & 0.77 & $0.67-0.88$ & 28208 & 167 & 45 & 51 & 28471 & 53.1 & $42.7-63.3$ & 99.4 & $99.3-99.5$ \\
\hline BZD***-hypnotics, during pregnancy & 18 & 0.06 & $0.04-0.10$ & 8 & 0.03 & $0.01-0.06$ & 28457 & 3 & 13 & 5 & 28478 & 27.8 & $10.7-53.6$ & 100 & $100-100$ \\
\hline $\begin{array}{l}\text { BZD***-hypnotics, dispensed from } 30 \text { days } \\
\text { before pregnancy or during pregnancy }\end{array}$ & & & & 14 & 0.05 & $0.03-0.08$ & 28452 & 8 & 12 & 6 & 28478 & 33.3 & $14.4-58.9$ & 100 & $99.9-100$ \\
\hline $\begin{array}{l}\text { BZD***-hypnotics, dispensed from } 60 \text { days } \\
\text { before pregnancy or during pregnancy }\end{array}$ & & & & 15 & 0.05 & 0.03-0.09 & 28451 & 9 & 12 & 6 & 28478 & 33.3 & $14.4-58.9$ & 100 & $99.9-100$ \\
\hline BZD***-antiepileptics, during pregnancy & 8 & 0.03 & $0.01-0.06$ & 9 & 0.03 & $0.02-0.06$ & 28468 & 1 & 0 & 8 & 28477 & 100 & $100-100$ & 100 & $100-100$ \\
\hline $\begin{array}{l}\text { BZD***-antiepileptics, dispensed from } 30 \\
\text { days before pregnancy or during pregnancy }\end{array}$ & & & & 9 & 0.03 & $0.02-0.06$ & 28468 & 1 & 0 & 8 & 28477 & 100 & $100-100$ & 100 & $100-100$ \\
\hline $\begin{array}{l}\text { BZD***-antiepileptics, dispensed from } 60 \\
\text { days before pregnancy or during pregnancy }\end{array}$ & & & & 9 & 0.03 & $0.02-0.06$ & 28468 & 1 & 0 & 8 & 28477 & 100 & $100-100$ & 100 & $100-100$ \\
\hline
\end{tabular}

1) Not in MoBa not in NorPD; N (A)

2) Only registered in NorPD; $N(B)$

3) Only registred in $\mathrm{MoBa} ; \mathrm{N}(\mathrm{C})$

4) Registered in both MoBA and NorPD; N (D)

* Sensitivity $=\mathrm{D} /(\mathrm{C}+\mathrm{D})$

$* *$ Specificity $=\mathrm{A} /(\mathrm{A}+\mathrm{B})$

*** BZD- benzodiazepine

Anatomical Therapeutic Chemical code (ATC code): opioids (N02A); antidepressants (N06A); BZD-anxiolytics (N05BA); BZD-hypnotics (N05CD) and BZDantiepileptics (N03AE) 
Validity of drug use recorded in NorPD when selfreported drug use was used as reference standard

Sensitivity of self-reported drug use was highest for antidepressants and BZD-antiepileptics and lowest for BZD-hypnotics (table 1). Women redeemed prescription of antidepressants during pregnancy in 200 of 299 who self-reported use of antidepressants during pregnancy in MoBa giving a sensitivity of $66.9 \%$ (table 1 ). Sensitivity increased to $80.9 \%$ and $87.0 \%$ when the period for dispensed prescription was expanded by 30 and 60 days prior to pregnancy, respectively. Specificity of self-reported drug use was lowest (98.7\%) for opioids. Specificity decreased to $98.2 \%$ and $97.6 \%$ when the period for dispensed prescription was expanded by 30 and 60 days prior to pregnancy, respectively.

General expansion of the time windows for dispensed drugs in the prescription database NorPD to include intervals 30 and 60 days before pregnancy led to higher sensitivity and lower specificity for all classes of drugs (table 1).

\section{DisCUSSION}

In this large population-based sample, we showed that use of prescription databases in measurements of exposure of dispensed antidepressants and BZDantiepileptics had high sensitivity and specificity when using self-reported use as reference standard. Lower sensitivity was observed for drugs often used intermittently as opioids, BZD-hypnotics and BZD-anxiolytics. Expansion of the exposure time window in the prescription database to include time before pregnancy led to higher sensitivity and lower specificity. When comparing prevalence of drug use in pregnancy measured in MoBa and NorPD we observe lower prevalence after self-report than registered in the prescription database.

Not surprisingly we observe lower prevalence of drug use when utilizing self-reported data compared to register data. There are several reasons for this. Drugs dispensed at the pharmacy need not be used by the pregnant woman. In addition women may not remember that they used drugs or they do not want to provide this information. When using the prescription database with different time windows and self-reported questionnaires as reference, we got a lower specificity and higher sensitivity when including intervals of 30 and 60 days before pregnancy. Women who were dispensed drugs before pregnancy may be truly unexposed if they stopped using the drug before pregnancy, but may have been misclassified as exposed if exposure was defined based on the prescription database with time before pregnancy used in the exposure definition. On the other hand, increase in sensitivity could mean that some women may have used these drugs during pregnancy. The prevalence of antidepressants, BZD and opioids use is relatively low. Greenland has pointed out that high specificity is more important than high sensitivity for the measured risk association when the prevalence of exposure is low (17). Thus it is important to minimize the number of truly unexposed drug users in the exposed group in studies of the drug safety in pregnancy.

For the drug classes other than antidepressants and antiepileptics, that is the drugs used intermittently and not chronically, expansion of time interval to include 60 days before pregnancy to define exposure in NorPD did increase sensitivity but not to a very high level. As an example we observed for opioids that 457 women did report use of opioids but only 245 were registered in NorPD. This means that almost one half were not registered in the NorPD even with such long time interval before pregnancy. This is maybe not so surprising since these analgesics are used intermittently and many women may have them in their closets for use when needed. The same may be true for anxiolytic hypnotic drugs.

\section{Strengths and limitations}

The "truth" regarding drug use is not available either in the prescription database or in the self-reported information on drug use. The choice of the selfreported drug use as a reference standard may have some weaknesses. The design and phrasing of the questions may have influenced the overall accuracy of self-reported drug use. In the questionnaires, the women were asked to write the trade names of drugs they had used for different illnesses. Open-ended questions on trade names of drugs can lead to lower accuracy $(18,19)$. The last questionnaire was post-delivery and recall accuracy regarding medication use might be influenced by the recall interval. The participants could write down more than one drug and in the same question they could tick for several periods of use. In some instances several drugs used in several periods made it difficult to disentangle which specific drug was used in which specific period. It is unfortunate that the questions were posed in this way. One example of drugs that commonly was reported simultaneously was opioids and triptanes.

In the present study, the study population was restricted to only women who agreed to participate in the MoBa study. This can lead to selection bias. As shown by Nilsen et al. (20) the proportion of nulliparous women aged 25-34 years was higher, and the proportion of smokers was lower in MoBa compared to the total population of pregnant women. An earlier study of Handal et al. (21) showed a higher proportion (2.9\%) of women using opioids measured in NorPD among all Norwegian pregnant women compared to the prevalence of opioid use $(2.1 \%)$ measured by the same data source in the present study. This suggests that our study population consumes less opioids and is healthier than the total pregnant population in Norway.

A strength of this study is the use of the unique personal identity number, which ensured valid data 
linkage between the questionnaire and prescription database. The completeness and accuracy of NorPD is high because of legislation and other incentives motivating pharmacies to collect and send the data electronically to the national database on all dispensed drugs to individuals in ambulatory care. Coverage of NorPD for total pharmacy records in Norway to individual outpatients is $100 \%$ (6).

\section{Other studies}

Some validation studies from the Nordic countries among pregnant women on drug exposure measured by information in prescription databases have been published $(4,5,8,22)$. In these studies prescription databases are compared with self-report, interview or with information from medical birth registries. Information from prescription databases was used as reference standard in some studies, but in others information was validated against other sources of drug exposure.

Overall, researchers have reported a higher accuracy of recall for medications used chronically in comparison with medication used as short-courses or episodically. In studies from Sweden and Norway dispensed drugs from the prescription databases were obtained prior to, during, and after the pregnancies and compared with data from the medical birth registries which collects information on drug use from standardized antenatal medical records $(4,5)$. The study from Sweden concluded that agreement was high for drugs used for chronic conditions (as antiepileptics and antidepressants) but low for occasional use (hypnotics and sedatives). The Norwegian study concluded that the medication use recorded in MBRN was poor compared with prescribed medicines registered in NorPD. In a Danish study, Olesen et al compared dispensed drugs from a prescription database with information on intake obtained from telephone interviews of pregnant women (22). The results also revealed that drugs used for chronic diseases during pregnancy were reported to be used, which was not the case for local or short-term used drugs. The findings that the sensitivity and specificity varied by therapeutic classes in our study correspond well with the results in these other studies.

Validity studies on drug exposure are important to perform. Use of different data sources may lead to different types of misclassification of drug exposure. By comparing data sources we get a greater understanding of the data in the different data sources and results from validity studies may be applied to evaluate results from other studies. A good example of this is a recently published study by Skurtveit et al. (7). This study also showed that inclusion of time before pregnancy to define exposure in early pregnancy led to lower specificity. Because of this a possible underestimation of the risk estimate of the association between use of SSRIs in early pregnancy and a serious condition in the newborn was overlooked.

\section{Conclusion}

In Norway we have two important sources on drug use during pregnancy. Both have their strengths and limitations, and validity studies give us better understanding of both sources. The current study indicates that the prescription data can give valid information on drugs used for chronic conditions. The sensitivity and specificity varied according to the psychotropic drug categories and the time windows considered.

\section{ACKNOWLEDGEMENTS}

The Norwegian Mother and Child Cohort Study is supported by the Norwegian Ministry of Health and the Ministry of Education and Research, NIH/NIEHS (contract no NO-ES75558), NIH/NINDS (grant no.1 UO1 NS 047537-01), and the Norwegian Research Council/FUGE (grant no. $151918 / \mathrm{S} 10)$. We are grateful to all the participating families in Norway who take part in this ongoing cohort study.

\section{REFERENCES}

1. Andrade SE, Gurwitz JH, Davis RL, et al. Prescription drug use in pregnancy. Am J Obstet Gynecol 2004; 191 (2): 398-407.

2. Engeland A, Bramness JG, Daltveit AK, Rønning M, Skurtveit S, Furu K. Prescription drug use among fathers and mothers before and during pregnancy. A population-based cohort study of 106000 pregnancies in Norway 2004-2006. Br J Clin Pharmacol 2008; 65 (5): 653-60.

3. Lee E, Maneno MK, Smith L, et al. National patterns of medication use during pregnancy. Pharmacoepidemiol Drug Saf 2006; 15 (8): 537-45.

4. Stephansson O, Granath F, Svensson T, Haglund B, Ekbom A, Kieler H. Drug use during pregnancy in Sweden - assessed by the Prescribed Drug Register and the Medical Birth Register. Clin Epidemiol 2011; 3: 43-50.

5. Espnes MG, Bjørge T, Engeland A. Comparison of recorded medication use in the Medical Birth Registry of Norway with prescribed medicines registered in the Norwegian Prescription Database. Pharmacoepidemiol Drug Saf 2011; 20 (3): 243-8.

6. Furu K, Wettermark B, Andersen M, Martikainen JE, Almarsdottir AB, Sørensen HT. The Nordic countries as a cohort for pharmacoepidemiological research. Basic Clin Pharmacol Toxicol 2010; 106 (2): 86-94.

7. Skurtveit S, Selmer R, Tverdal A, Furu K, Nystad W, Handal M. Drug exposure: inclusion of dispensed drugs before pregnancy may lead to underestimation of risk associations. J Clin Epidemiol 2013; 66 (9): 964-72. 
8. Kallen B, Nilsson E, Olausson PO. Antidepressant use during pregnancy: comparison of data obtained from a prescription register and from antenatal care records. Eur J Clin Pharmacol 2011; 67 (8): 839-45.

9. Kieler H, Artama M, Engeland A, et al. Selective serotonin reuptake inhibitors during pregnancy and risk of persistent pulmonary hypertension in the newborn: population based cohort study from the five Nordic countries. BMJ 2012; 344: d8012.

10. Koren G, Nordeng H. SSRIs and persistent pulmonary hypertension of the newborn. BMJ 2012; 344 : $\mathrm{d} 7642$.

11. Magnus P, Irgens LM, Haug K, Nystad W, Skjærven R, Stoltenberg C. Cohort profile: the Norwegian Mother and Child Cohort Study (MoBa). Int J Epidemiol 2006; 35 (5): 1146-50.

12. Irgens LM. The Medical Birth Registry of Norway. Epidemiological research and surveillance throughout 30 years. Acta Obstet Gynecol Scand 2000; 79 (6): 435-9.

13. WHO Collaborating Centre for Drug Statistics Methodology. ATC Classification Index with DDDs 2013. WHO Collaborating Center for Drug Statistics Methodology, 2012.

14. Questionnaires from MoBa. Norwegian Institute of Public Health. http://www.fhi.no/eway/default.aspx?pid=240\&trg=MainContent_6894\&Main_6664=6894:0:25,7372:1:0:0::: 0:0\&MainContent_6894=6706:0:25,7375:1:0:0:::0:0. Accessed 17.03 2014.

15. Grzeskowiak LE, Gilbert AL, Morrison JL. Exposed or not exposed? Exploring exposure classification in studies using administrative data to investigate outcomes following medication use during pregnancy. Eur $J$ Clin Pharmacol 2012; 68 (5): 459-67.

16. Vollset SE. Confidence intervals for a binomial proportion. Stat Med 1993; 12 (9): 809-24.

17. Greenland S. Basic methods for sensitivity analysis of biases. Int J Epidemiol 1996; 25 (6):1107-16.

18. Validity of pharmacoepidemiologic drug and diagnosis data. In: Strom BL, ed. Pharmacoepidemiology, 4th edn. Chichester: John Wiley \& Sons; 2006: 709-765..

19. Mitchell AA, Cottler LB, Shapiro S. Effect of questionnaire design on recall of drug exposure in pregnancy. Am J Epidemiol 1986; 123 (4): 670-6.

20. Nilsen RM, Vollset SE, Gjessing HK, et al. Self-selection and bias in a large prospective pregnancy cohort in Norway. Paediatr Perinat Epidemiol 2009; 23 (6): 597-608.

21. Handal M, Engeland A, Rønning M, Skurtveit S, Furu K. Use of prescribed opioid analgesics and co-medication with benzodiazepines in women before, during, and after pregnancy: a population-based cohort study. Eur J Clin Pharmacol 2011; 67: 953-60.

22. Olesen C, Søndergaard C, Thrane N, Nielsen GL, de Jong-van den Berg L, Olsen J. Do pregnant women report use of dispensed medications? Epidemiology 2001; 12 (5): 497-501. 